\title{
Post-publication problems: how to proceed when there's no record of IACUC approval?
}

$\mathrm{D}$ r. Yoshihiro Katayama successfully completed his $\mathrm{PhD}$ research at Great Eastern University and returned home to Japan and his new job as an assistant professor of molecular biology. His mentor during his PhD studies, Dr. Henry Miller, was rightly proud of Katayama's work and looked forward to the publication of their final collaborative studies. When that research was finally published, it was well received and highlighted in a university news release. The chairman of the Great Eastern IACUC, Dr. Larry Covello, read the release and then read the published article. Covello could not remember any such study being approved by the IACUC, but the article clearly stated that the research had received IACUC approval. Covello asked the IACUC office to check Miller's IACUC files. No record of that research could be found. There was no record of Katayama being a principal investigator, so Covello asked Miller for an explanation. Miller said he was sure that Katayama had submitted an IACUC protocol, but after a search of IACUC and laboratory records, it became clear that Katayama had inadvertently used the IACUC approval number of one of Miller's other protocols for the research that led to the publication. There had never been an IACUC review of that work.
Neither Miller nor Katayama had ever caused a problem for the IACUC. However, the work was performed without IACUC approval or oversight; the findings were important; and they were published in a prestigious journal. What, if anything, do you think Miller and the IACUC should do?

\section{Jerald Silverman}

University of Massachusetts Medical School, Worcester, Massachusetts, USA.

e-mail: Jerald.Silverman@umassmed.edu

Published online: 26 February 2018 https://doi.org/10.1038/s41684-018-0004-0

\section{Investigation, reporting, and program improvement}

\footnotetext{
T he Institutional Animal Care and Use Committee (IACUC) should rapidly conduct an investigation to gather complete information about what happened. Questions that need to be answered include: What species was involved and is that species regulated by the United States Department of Agriculture (USDA)? What was the funding source for the research and did it involve funding from the National Institutes of Health or the National Science Foundation? How many animals were involved? What procedures were performed on the animals and by whom? Were those same species, people, and procedures approved under another related protocol? Were the animals housed in a centralized animal facility or an investigator-managed, satellite facility and what prevented husbandry, veterinary, and post-approval monitoring (PAM) staff from noticing that unapproved procedures were taking place? Were the animals from an in-house production colony or purchased from an external vendor without first verifying that an IACUC-approved protocol was in place? Had all members of the research team been trained about requirements for prior IACUC approval? It is critical to learn where and how the system broke
}

down to identify what could prevent similar occurrences in the future.

Once it becomes clear that Public Health Service-funded animal activities have taken place without IACUC approval, the Office for Laboratory Animal Welfare (OLAW) must be notified promptly. According to NOT-OD-13-044, "it is appropriate to submit a preliminary report prior to the completion of a full investigation and implementation of a corrective plan". Institutions must also provide a final report including a detailed explanation of the circumstances and actions taken. The final report must be signed by the Institutional Official (IO) and submitted either via email in PDF format or by fax. If the project involved a USDA-regulated species, the IACUC and IO should review USDA's December 2017 Technical Note titled "Incentives for Identifying, Reporting, Correcting, and Preventing Noncompliance with the Animal Welfare Act" for advice on reporting to USDA. Finally, most animal-related research articles include a statement about IACUC approval. Assuming that occurred in this scenario, Katayama should contact the journal to inform them that the project had not been IACUC-approved and let the journal determine whether a clarification needs to be published.

Based on the results of the investigation, the IACUC and IO should identify any programmatic changes appropriate to prevent problems like this from reoccurring. Does a PAM program need to be implemented or improved? Is the training program adequate to ensure all research team members know their responsibility to conduct animal procedures as described in IACUC-approved protocols? Do some individuals need refresher training? Do animal procurement and protocol transfer procedures involve a method of verifying IACUC approval? Do grant application processes include a method to verify grant congruency with IACUC-approved procedures? The IACUC and IO should implement changes as needed to prevent a repeat of the noncompliance while minimizing additional regulatory or training burden on the faculty and staff.

Todd A. Jackson

Oklahoma State University, Stillwater, OK, USA.

e-mail: todd.a.jackson@okstate.edu

Published online: 26 February 2018

https://doi.org/10.1038/s41684-018-0005-z 